\title{
Abstract \\ From Single Nanowires to Smart Systems: Different Ways to Assess Food Quality ${ }^{+}$
}

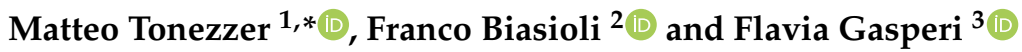 \\ 1 IMEM-CNR, Sede di Trento-FBK, Via alla Cascata 56/C, 38123 Povo, Trento, Italy \\ 2 Research and Innovation Centre, Fondazione Edmund Mach, 38010 San Michele all'Adige, Trento, Italy; \\ franco.biasioli@fmach.it \\ 3 Research and Innovation Centre, Department of Food Quality and Nutrition, Fondazione Edmund Mach, \\ Via Edmund Mach 1, 38010 San Michele all'Adige, Trento, Italy; flavia.gasperi@fmach.it \\ * Correspondence: matteo.tonezzer@cnr.it \\ + Presented at the 1st International Electronic Conference on Chemical Sensors and Analytical Chemistry, \\ 1-15 July 2021. Available online: https:/ / csac2021.sciforum.net.
}

check for updates

Citation: Tonezzer, M.; Biasioli, F.; Gasperi, F. From Single Nanowires to Smart Systems: Different Ways to Assess Food Quality. Chem. Proc. 2021, 5, 29. https://doi.org/10.3390/ CSAC2021-10605

Academic Editor: Ye Zhou

Published: 5 July 2021

Publisher's Note: MDPI stays neutral with regard to jurisdictional claims in published maps and institutional affiliations.

Copyright: (c) 2021 by the authors. Licensee MDPI, Basel, Switzerland. This article is an open access article distributed under the terms and conditions of the Creative Commons Attribution (CC BY) license (https:// creativecommons.org/licenses/by/ $4.0 /)$.

\begin{abstract}
Recently, low-dimensional (1D, 2D) nanostructured materials have been attracting more and more interest as building blocks for innovative systems. Metal oxide nanowires are one of the most widely used materials for solid-state gas sensors, as they are simple to make, inexpensive, and sensitive to a wide range of gases and volatiles. Unfortunately, their broad sensitivity has a price to pay, which is very low selectivity. Fortunately, this flaw is not a problem for all applications. Where the boundary conditions are defined and "simple" (only the presence of a target gas is expected, without any interfering gases), a single traditional chemiresistor may be the best choice, while in cases where the variables are many, it is better to use an intelligent system. In this paper, we will show a resistive sensor based on a single $\mathrm{SnO}_{2}$ nanowire which, working at three temperatures (200, 250 , and $300{ }^{\circ} \mathrm{C}$ ), is able to detect tens of ppb of ammonia $\left(30 \mathrm{ppb}\right.$ at $\left.300{ }^{\circ} \mathrm{C}\right)$. The limit of detection (LoD) was calculated as $3 \mathrm{~N} / \mathrm{S}$, where $\mathrm{N}$ is the standard deviation of the sensor signal in air and $\mathrm{S}$ is the sensor sensitivity. We will show that the performance of this nanosensor is excellent and can be used in various applications, including agri-food quality monitoring. We will demonstrate that the $\mathrm{SnO}_{2}$ nanowire in a thermal gradient can act as a nano-electronic nose thanks to machine learning algorithms. The single nanowire-based sensor can estimate the total viable count with an error of $2.32 \%$ on mackerel fish samples stored at room temperature $\left(25^{\circ} \mathrm{C}\right)$ and in a fridge $\left(4^{\circ} \mathrm{C}\right)$. The integration of such a small (less than one square $\mathrm{mm}$ ) and cheap device into the food supply chain would greatly reduce waste and the frequency of food poisoning.
\end{abstract}

Keywords: gas sensors; metal oxide; nanowire; electronic nose; machine learning

Supplementary Materials: The following are available online at https:/ /www.mdpi.com/article/10 .3390/CSAC2021-10605/s1.

Author Contributions: Conceptualization, M.T.; methodology, M.T.; software, M.T.; validation, M.T., F.B. and F.G.; formal analysis, M.T.; investigation, M.T.; resources, F.B., F.G.; data curation, M.T.; writing-original draft preparation, M.T.; writing—review and editing, M.T., F.B. and F.G.; visualization, M.T.; supervision, F.B. and F.G.; project administration, F.B. and F.G.; funding acquisition, F.B. and F.G. All authors have read and agreed to the published version of the manuscript.

Funding: This research received no external funding.

Institutional Review Board Statement: Not applicable.

Informed Consent Statement: Not applicable. 
Data Availability Statement: The data presented in this study are openly available in Open Science Framework at doi:10.17605/OSF.IO/83SMW.

Conflicts of Interest: The authors declare no conflict of interest. 